\title{
CORE QUEST: Factors Advertising Creative Should Pursue as Business Art
}

\author{
Chulho Kim* \\ Associate Professor, Department of Advertising \& PR, Cheongju University, South Korea
}

\begin{abstract}
The perspective towards advertising in modern society is based on a balance between the micropractical perspective that views advertising as an efficient method contributing to corporate objective attainment and the macro-environmental perspective that views advertising as one of many factors constructing the social system that endlessly communicates with society. Also, advertising creative's basic roles are a managerial role to mitigate consumers' defense mechanisms and create a primary contact point and a sociocultural role to continuously contact mutually influence society.

From this perspective, this paper suggests the nine factors advertising creative should consider with the concept of CORE QUEST. These are: Contact point expansion, Originality, Relevance, Empathy orientation, $\boldsymbol{Q}$ uantification, Unit-objective oriented tasks, Ethicality, Strategic, Target voice expression.

Conclusively, as the nine orientation points are systematically related to each other with an interdisciplinary, integrated perspective, advertising creative should consider the artistic factor based on creativity, the psychological factor for persuading people, the communication factor to share meaning with society, the marketing factor related to business objectives and etc. from a balanced point between the macro environmental perspective and the micro-practical perspective.
\end{abstract}

Keywords: Advertising Creative; Business Art; CORE QUEST; Macro-Environmental Perspective; MicroPractical Perspective; Shared Value Expectation;

\section{Understanding Advertising Phenomena: Macro-Environmental Perspective Vs. Micro-Practical Perspective}

Creative in advertising is business art based on artistry and creativity that draws forth a primary contact point between advertisers and consumers. However, in modern society advertising's key existence value is not limited to a sector of social science like marketing and communication. Rather, its existence value is placed at the expansion and execution of the interdisciplinary perception in which it is a major social component that reciprocally interacts with culture, philosophy, anthropology, sociology, art, design, and etc. related fields.

Thus, in order to understand the advertising phenomena, reminding to maintain a balance between the micro-practical perspective that focuses on advertising's role as achieving corporate objectives, and the macro-environmental perspective that focuses on continuous communication among various social aspects such as culture, art, economy, environment, education and etc. should be preceded.

Also, attention should be given to the fact that the connecting points between the macroenvironmental perspective and the micro-practical perspective are focused on consumers, media, messages, the ecological environment and etc. and that there is continuous mutual negotiation and influence between the two.

For example, let's think about the phenomena in which a society's religion, culture, values and etc. influence the content and communication of advertising content, and the phenomena in which matters of interest gain popularity or become well known through advertisements are recreated and reconstructed in the corresponding society's life naturally. These phenomena naturally show that factors of the macro-environmental perspective and the micro-practical perspective continuously influence each other and systematically coexist in society.

It also naturally reminds the importance of symbiotic value[1], which is 'a value in which actors as social beings pursue ideal, harmonic symbiosis based on mutual understanding and trust in situations 
where political, social, and environmental variety overlaps and coexists', in the process of understanding the advertising phenomena.

\section{Advertising Creative: Pursuing CORE QUEST}

Then, what role does creative conduct in advertising?

From the micro-practical perspective, creative in advertising "has managerial significance in its strategic value by ultimately expanding friendly contact points with consumers by securing consumers' initial awareness and attention in the process of planning and executing marketing communication campaign"'[2].This means that advertising creative's role is relaxing the defense mechanism consumers have towards excessive information and securing primary contact points for communication. This means that advertising creative's role should be to relax the defense mechanism consumers have towards excessive information and to secure primary contact points for communication.

Research related to the effect of creative are the effect of visual figures from verbal rhetorical figures[3], the effect of Visualization Strategy towards in formativeness, perceived quality, and likelihood of use[4], the favorable effect towards a combination of visual and verbal[5], positive effect of visual factors constructing creative[6], and etc. Although focused on visual and verbal effects, these researches imply that creative expressed by visual and verbal can be used as an efficient tool to induce positive attitudes from people.

However, from the macro-environmental perspective, we should not forget the fact that advertising creative should create empathy with society and furthermore pursue the sharing and expansion of value expectation considering social, cultural, traditional environment differences. Thus, when considering shared value expectation is "value expectation that is shared through interaction among related subjects to establish values for a specific society/organization and to expand these values quantitatively and qualitatively"[7], the macro-environmental approach reminds that advertising creative should contribute to creating a space for empathy between the message sender and receiver and ultimately contribute to expanding the extent of shared value expectation among message and information related subjects.

Then what should be considered in advertising creative? To what relationship do we have to pay attention among those considered and the related fields such as cultural anthropology, art, creativity, social sciences, art and etc. with a macro-environmental perspective derived from the interdisciplinary perspective? This paper looks at this with the concept of CORE QUEST[8].

The first is about 'contact point expansion'. Advertising creative should function as a fundamental contact point that attracts consumers' attention. This is because expansion of contact points is closely related to reciprocity of interaction. From an interdisciplinary perspective, this is closely related to the role of communication to 'share meaning' [9]. Moreover, from the perspective that contact points themselves function as media[10], contribution through expansion of contact points is closely related to media's essence and its basic role as well.

The second is 'originality'. This is linked to differentiation and creativity, original characteristics of ad creative. From the perspective viewing advertising creative as business art, it is also closely related to expression of artistry.

The third is 'relevance'. Relevance required from advertising creative is closely related to logical relevance that creative should have as business art. Moreover, relevance is a concept closely related to artistic needs such as ideas' sensual(visual/auditory), symbolic messagification.

Fourth is 'empathy-orientation'. Empathy means 'a status in which subjects of consciousness and action share the experience by agreeing with the target object's perceptual, emotional, and behavioral status or reaction'[11]. Therefore, when saying that creative in advertising should be oriented towards empathy, it means that advertising creative should help the consumers as subjects of consciousness and action experience/agree with the perceptual, emotional, and behavioral status or reaction intended by ideas or messages created through creative.

From an interdisciplinary perspective, the exchange of reciprocity through empathy is highly related to communication's function, and moving peoples' minds is highly related to psychology's function. When considering the importance of creative's localization strategy[12] and the social values, 
customs, etc. of message appeal targets, culture, religion, anthropology, and the like are closely related with the macro-environmental perspective.

Fifth is the possibility of 'quantification'. This means that advertising creative should contribute to measuring effects connected to advertising goals or marketing communication goals. VAC MACE (Variablizing Advertising Creative for Measured Advertising Creative Effects)[13]and QAC MACE(Quantitating Advertising Creative for Measured Advertising Creative Effects)[14], which are based on the necessity of quantitative advertisement effect measurement, support this concept. From an interdisciplinary perspective, the possibility of advertising creative's quantification is closely related to research, statistics, and etc. fields.

Sixth is 'unit-objective oriented tasks'. This is orientation based on the micro-practical perspective towards advertising. Thus, advertising creative must have its independent goal, and this goal of advertising creative must essentially contribute to the advertising goal or the marketing communication goal.

Seventh is 'ethicality'. Because advertising creative is essentially based on commerciality, ethicality and consideration of virtue values that focus on actions based on good human virtue[1]are natural orientation points. Ethicality is related to corporate social responsibility(CSR)[15], advertisers' social responsibility(ASR), and media companies' social responsibility(MSR).This perspective supports previous research[16]that pursuing decision making based on ethicality is an actor-centered and ethical sense-centered social practice rather than pursuing economic profits. From an interdisciplinary and macro perspective, it is the concept in which ethics, philosophy, environment, and the like have been integrated to help understand the advertising phenomena.

Eighth is the 'strategic trait'. This is a concept connected to the establishment and execution of marketing strategy or corporate management strategy. Therefore, it originates from advertising strategy that consists of two key axes, creative strategy and media strategy.

Ninth is 'target voice expression'. Because creative is ultimately closely related to consumers' changes in attitude, this pursuit means that advertising creative should messagify what the target wants from the target's perspective.

Table1. Factors considered in planning advertising creative and their interdisciplinary relatedness

\begin{tabular}{|l|l|}
\hline Factors Considered in Planning Ad Creative & \multicolumn{1}{c|}{ Interdisciplinary Relatedness } \\
\hline Contact point Expansion & Communication, Media, Consumer Behavior, Psychology \\
\hline Originality & Art, Creativity \\
\hline Relevance & Design, Visual Image \\
\hline Empathy Orientation & $\begin{array}{l}\text { Cultural anthropology, Communication, } \\
\text { Consumer Behavior, Psychology }\end{array}$ \\
\hline Quantification & Quantitative Research, Statistics, Math \\
\hline Unit-Objective Oriented Tasks & Marketing \\
\hline Ethicality & Ethics, Philosophy, Environment, Ecology \\
\hline Strategic Trait & Business, Marketing \\
\hline Target Voice Expression & Consumer Behavior, Psychology \\
\hline
\end{tabular}

\section{InTERdisciplinary ANd InTEgrated Symbiotic PerSPECTIVE NeEded}

The following points must be noted:

First, as seen in <Table 1>, each factor considered is closely related to adjacent fields from an interdisciplinary perspective. View the factors advertising creative pursues from adjacent fields' perspective as a reverse approach.

From a communication perspective, contact point expansion, empathy orientation and etc. could be interdisciplinarily related. This is because communication's basic background is transferring information and sharing meaning.

From an artistic perspective, originality and relevance could be considered. This is because originality is related to differentiated ideas and appropriateness is related to the acceptability of the message expressed through design, visuals, and videos.

From an environmental, ethical, and philosophical perspective, they can be closely related to ethicality advertising creative must pursue, and from the information receivers' perspective, target voice expression, contact point expansion, empathy orientation and etc. can be closely related. 
From a psychological perspective, actions to read peoples' minds and understand attitudes such as empathy orientation, expanding cognitive contact point, expression of consumers' voices could be closely related.

From a business and marketing perspective, these could be closely related to unit objective orientation and strategic factors, from a research and methodology perspective, these could be closely related to quantification and objective orientation.

From a cultural anthropology perspective, this could be closely related to empathy orientation, ethicality, and contribution to contact point expansion and the like with considering the information receiver's environment.

Table2. Interdisciplinary Perspectives seeing factors advertising creative pursues

\begin{tabular}{|l|l|}
\hline \multicolumn{1}{|c|}{$\begin{array}{c}\text { Interdisciplinary Perspectives related with Adjacent } \\
\text { Fields }\end{array}$} & \multicolumn{1}{c|}{ Factors Advertising Creative Pursues } \\
\hline Communication Perspective & Contact Point Expansion, Empathy Orientation \\
\hline Artistic Perspective & Originality, Relevance \\
\hline Environmental, Ethical, and Philosophical Perspective & Ethicality \\
\hline Information Receivers' Perspective & $\begin{array}{l}\text { Target Voice Expression, Contact point } \\
\text { Expansion, Empathy Orientation }\end{array}$ \\
\hline Psychological Perspective & $\begin{array}{l}\text { Empathy Orientation, Expanding Cognitive } \\
\text { Contact Point, Expression of Consumers' } \\
\text { Voices }\end{array}$ \\
\hline Business and Marketing Perspective & Unit-Objective Oriented Tasks, Strategic Trait \\
\hline Research and Methodology Perspective & Quantification, Unit-Objective Oriented Tasks \\
\hline Cultural Anthropology Perspective & $\begin{array}{l}\text { Empathy orientation, Ethicality, Contact point } \\
\text { Expansion }\end{array}$ \\
\hline
\end{tabular}

Second, the nine orientation points can, as needed, be systematically connected or overlap. This means that adverting's macro-environmental, micro-practical effect and influence could be a result of the nine factors interacting with each other. Originality was aforementioned as a factor advertising creative should pursue, but the originality of the message does not always link to creative.

For example, even for new attention attracting visuals or shocking videos, if these are not appropriate for their fundamental objectives, such as not moving people due to a lack of contact points with the consumer, being unethical, failing to induce empathy with others, and so on, the message cannot be regarded as creative.

Conclusively, the artistic factor based on creativity, the psychological factor for persuading people, the communication factor to share meaning with people, the marketing factor related to business objectives and etc. of advertising creative must be considered from a balanced point between the macro-environmental perspective and the micro-practical perspective. The necessity to view from an interdisciplinary, integrated symbiotic perspective must be remembered as well.

\section{REFERENCES}

[1] Kim, Jisoo \& Kim, Chulho (2016). Perspectives to Understand the Relationshipbetween Religion and Communication International Journal ofJournalism and Mass Communication. 3(1). 117.pp.1 4. p.3. doi:http://dx.doi.org/10.15344/2349-2635/2016/117

[2] Kim, Chulho (2012). The Effect of Ad Exposure Motivation and Creative Techniques on Attitude toward Ad and Reinforcing Ad Exposure Motivation. Design Forum, 34, pp.469 480.

[3] McQuarrie, Edward F., \& Mick, David G. (2003). Visual and Verbal Rhetorical Figures under Direct Processing Verses Incidental Exposure to Advertising. Journal of Consumer Research. 29. March. pp.579 587.

[4] Hill, Donna J., Jeff Blodgett, Robert Baer, Kirk Wakefield (2004). An Investigation of Visualization and Documentation Strategies in Services Advertising. Journal of Service Research. 7(2). (November). pp.167 180.

[5] Sojka, Jane Z. \& Giese, Joan L. (2006). Communicating through pictures and words: understanding the role of affect and cognition in processing visual and verbal information. Psychology \& Marketing. 23(12). pp.995 1014.

[6] Alain, Decrop (2007). The Influence of Message Format onthe Effectiveness of Print Advertisements for TourismDestinations. International Journal of Advertising,26(4). pp.505 525. 
[7] Kim, Chulho (2015). Shared Value Expectation on Lifelong Education. Journal of Digital Convergence. 13(12). pp.325 336.

[8] Kim, Chulho (2017). Understanding Advertising Planning with Interdisciplinary, Integrated Symbiology. Hankyungsa. Seoul. South Korea. pp.213 216.

[9] Pearson, J., \& Nelson, P. (2000). An introduction to human communication: Understanding and sharing. Boston, MA: McGraw-Hill.

[10] Kim, Chulho (2013). An Exploratory Study on Measuring Value Expectation As a Motivator to Use Digital Signage, Journal of Korea Design Knowledge, 28, pp.79 90.

[11] Kim, Chulho (2017). Understanding Advertising Planning with Interdisciplinary, Integrated Symbiology. Hankyungsa. Seoul. South Korea. p.136.

[12] Sheth, Jagdish. 1986. Global markets or global competition?. Journal ofConsumer Marketing, 3(2). pp.9 11, https://doi.org/10.1108/eb008157

[13] Kim, Chulho (2017). Understanding Advertising Planning with Interdisciplinary, Integrated Symbiology. Hankyungsa. Seoul. South Korea. p.209.

[14] Kim, Chulho (2017). Understanding Advertising Planning with Interdisciplinary, Integrated Symbiology. Hankyungsa. Seoul. South Korea. p.210.

[15] Carroll, A. B. 1979. A three-dimensional conceptual model of corporate performance. Academy of Management Review. 4(4), pp.497 505.

[16] Kim, Jisoo \& Kim, Chulho (2017). Three Perspectives about Ethical Value inAdvertising Business. International Journal ofJournalism and Mass Communication. 4(1). 124. pp.1 6. doi: https://doi.org/10.15344/2349-2635/2017/124 